\title{
Grats

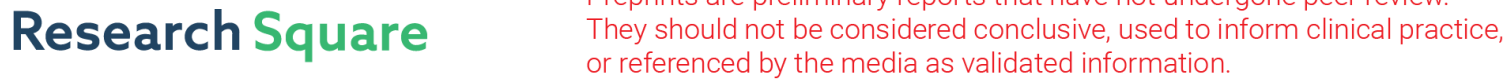 \\ CD69-0xLDL Ligand Engagement Induces Programmed Cell Death 1 (PD-1) Expression in T Lymphocytes
}

\section{Maria Jimenez-Fernandez}

Spanish National Cardiovascular Research Center: Fundacion Centro Nacional de Investigaciones Cardiovasculares Carlos III

\section{Cristina Rodriguez-Sinovas}

Institut d'Investigació Biomèdica Sant Pau IIB Sant Pau: Hospital de la Santa Creu i Sant Pau Institut de Recerca

\section{Laia Canes}

Institut d'Investigació Biomèdica Sant Pau IIB Sant Pau: Hospital de la Santa Creu i Sant Pau Institut de Recerca

\section{Carme Ballester-Servera}

Institut d'Investigació Biomèdica Sant Pau IIB Sant Pau: Hospital de la Santa Creu i Sant Pau Institut de Recerca

\section{Alicia Vara}

Hospital Universitario de la Princesa

\section{Silvia Requena}

Hospital Universitario de la Princesa

Hortensia de la Fuente

Hospital Universitario de la Princesa

\section{Jose Martinez-Gonzalez}

Institut d'Investigació Biomèdica Sant Pau IIB Sant Pau: Hospital de la Santa Creu i Sant Pau Institut de Recerca

\section{Francisco Sanchez-Madrid ( $\nabla$ fsmadrid@salud.madrid.org )}

Hospital Universitario de la Princesa https://orcid.org/0000-0001-5303-0762

\section{Research Article}

Keywords: CD69 leukocyte activation receptor, oxLDL, cardiovascular disease, Programmed Death-1 (PD1), anti-inflammatory response, inflamed aorta.

Posted Date: February 28th, 2022

DOI: https://doi.org/10.21203/rs.3.rs-1373760/v1 
License: (c) (i) This work is licensed under a Creative Commons Attribution 4.0 International License. Read Full License 


\section{Abstract}

The mechanisms that control the inflammatory-immune response play a key role in tissue remodeling in cardiovascular diseases. T cell activation receptor CD69 binds oxidized low-density lipoprotein (oxLDL), inducing the expression of anti-inflammatory NR4A nuclear receptors and modulating inflammation in atherosclerosis. To understand the downstream T cell responses triggered by the CD69-oxLDL binding, we incubated CD69-expressing Jurkat T cells with oxLDL. RNA sequencing revealed a differential gene expression profile dependent on the presence of CD69 and the degree of LDL oxidation. CD69-oxLDL binding induced the expression of NR4A receptors (NR4A1 and NR4A3), but also PD-1. These results were confirmed using oxLDL and an agonistic monoclonal antibody against CD69. CD69-mediated induction of PD-1 and NR4A3 was dependent on NFAT. Silencing NR4A3 slightly increased PD-1 levels, suggesting a potential regulation of PD1 by this receptor. Moreover, expression of PD-1, CD69 and NR4A3 were increased in human arteries with chronic inflammation compared to healthy controls, with a strong correlation between PD-1 and CD69 mRNA expression $(r=0.655 P<0.0001)$. Our results underscore a novel mechanism of induction of PD-1, independent of TCR, signaling that might contribute to the role of CD69 in the modulation of inflammation and vascular remodeling in cardiovascular diseases.

\section{Introduction}

The early lymphocyte activation antigen CD69 is a type II C-lectin membrane receptor readily induced upon leukocyte stimulation. Initial in vitro studies and the presence of CD69 on infiltrating leukocytes of different chronic inflammatory diseases were consistent with a pro-inflammatory role. However, growing evidence from in vivo analyses in mice lacking CD69 highlighted its role as a molecular brake to control exacerbated inflammatory responses[1]. Animal models including collagen-induced arthritis, autoimmune experimental myocarditis, allergic asthma, and colitis, among others, clearly established that CD69 exerts an immune-regulatory and protective role in inflammation [1-3]. CD69 acts through different mechanisms, mainly by inhibiting Th17 cell differentiation and regulating the Th17/ Treg cell balance. Hence, expansion of Th17 cell activity was observed in the absence of CD69; conversely, the suppressive function of CD4 + CD25 + FoxP3 + Tregs was diminished in CD69-deficient mice, revealing the importance of CD69 expression on this T cell subset [4]. The mechanisms by which CD69 controls Treg activity include upregulation of TGF- $\beta[3,5]$, elevated production of the cytokine IL-10 and expression of GITR, CD38, ICOS, and CTLA-4 [6]. CD69 is required for the expansion of Tregs in the thymus (tTregs) through the regulation of BIC/microRNA 155 and its target, suppressor of cytokine signalling 1 (SOCS-1) [7].

Understanding the pathophysiologic function of CD69 has been complicated by the absence of known ligands. Recently, CD69 was identified as an oxidized low-density lipoprotein (oxLDL) receptor in human T lymphocytes. OxLDL-CD69 binding triggers a protective effect, enhancing the anti-inflammatory transcription factors NR4A1 and NR4A3 (NOR-1), downregulating proinflammatory cytokines and promoting Treg differentiation, thereby modulating atherosclerosis [8]. 
An increasingly number of immunoregulatory molecules such as CTLA-4, PD-1, ICOS, LAG-3, TIGIT, etc., limit the activity and proliferation of $T$ lymphocytes $[9,10]$. The inhibitory receptor programmed cell death-1 (PD-1, CD279) is a key therapeutic target to treat immune and inflammatory disorders as well as to stimulate the antitumor immune response [11]. PD-1 and its ligands PD-L1 (B7-H1, CD274) and PD-L2 (B7-DC, CD273) belong to the B7-CD28 family and are highly regulated during normal immune responses [12].

Here, we report that the binding of oxLDL to CD69 induces the expression of PD-1 through the activation of transcription factor nuclear factor of activated T cells 1 (NFAT) in human T cells. Analysis of human inflammatory artery samples showed a high expression of CD69 and PD-1 and strong correlation between them. Our data demonstrate that PD-1 upregulation is a downstream mechanism involved in the negative regulation of the inflammatory response upon CD69-ligand engagement.

\section{Materials And Methods}

\section{Cell cultures}

We employed the human T lymphocyte Jurkat cell line stably transfected or not with CD69 (JKwt and JKCD69, respectively). The cells were maintained with RPMI 1640 + GlutaMAX ${ }^{\text {TM }}$ (Gibco) supplemented with $10 \%$ of heat-inactivated fetal bovine serum (FBS) (GE Healthcare Hyclone,), $0.1 \mathrm{U} / \mathrm{ml}$ penicillin and streptomycin (Lonza) and the selection antibiotic geneticin G418 (InvivoGen) at 0.5mg/ml. Both cell lines were incubated at $1 \cdot 10^{6} \mathrm{cells} / \mathrm{ml}$ with lipoproteins in their native or oxidized form at a concentration of 50 $\mu \mathrm{g} / \mathrm{ml}$ in $2 \%$ FBS medium the time indicated in each experiment.

\section{Low density lipoproteins (LDL) isolation and oxidation.}

Native LDL (nLDL) were isolated from pooled plasma of healthy blood donors of the Barcelona area [13]. The procedure was approved by the local ethics committee and was conducted in accordance with the Declaration of Helsinki. Briefly, pooled plasma was centrifuged $\left(80,000 \cdot \mathrm{g}\right.$ for 30 min at $\left.4^{\circ} \mathrm{C}\right)$ to remove chylomicrons. LDL ( $\mathrm{d}=1.019-1.063 \mathrm{~g} / \mathrm{mL})$ were isolated by potassium bromide density-gradient ultracentifugation using a Beckman-Coulter Optima ${ }^{\mathrm{TM}} \mathrm{L}-100$ XP ultracentrifuge and a Beckman 50.2 Ti rotor (Beckman Coulter) at 36,000 rpm for $18 \mathrm{~h}$ at $4^{\circ} \mathrm{C}(\mathrm{gmax}=156,000)$. The LDL fraction was dialyzed four times against 200 volumes of PBS for $24 \mathrm{~h}$. All solutions were deoxygenated by $\mathrm{N}_{2}$ bubbling. LDL were sterilized by filtration through a low protein-binding non-pyrogenic filter (Millex-GV, Millipore). Oxidized LDL (oxLDL) with different degrees of oxidation were prepared by exposing nLDL to $10 \mu \mathrm{M}$ $\mathrm{CuSO}_{4}$ at $37{ }^{\circ} \mathrm{C}$ for increasing times. LDL were stored at $4{ }^{\circ} \mathrm{C}$ and protected from exposure to light. The content of protein (BCA protein assay ${ }^{\mathrm{TM}}$, Pierce) and cholesterol (Cholesterol Assay Kit ${ }^{\mathrm{TM}}$, Abcam) was determined by colorimetric assays. LDL were free from contamination from other lipoproteins (as determined by electrophoresis) or endotoxin (as determined by a Limulus assay) (Chromogenic Endotoxin Quan kit ${ }^{\mathrm{TM}}$, Pierce). Thiobarbituric acid-reactive substances (TBARS) content of LDL were used as an indirect evaluation of lipid peroxidation [13]. In the present study we used nLDL (TBARS below 1 
nmol malonaldehyde (MDA)/mg of LDL protein), moderately oxidized LDL (moxLDL; TBARS around 10 nmol MDA/mg of LDL protein) and highly oxidized LDL (hoxLDL; TBARS between 25 and $50 \mathrm{nmol}$ MDA/mg of LDL protein).

\section{mRNA extraction and RNA-seq analysis}

For experiments aimed to analyse mRNA levels, cells were incubated for $45 \mathrm{~min}, 4$ and $8 \mathrm{~h}$ under the following conditions: without $L D L$, with $\mathrm{nLDL}$ or with oxLDL. Then, the cells were collected, rinsed once with phosphate-buffered saline (PBS) and preserved in QIAzol Lysis Reagent (Qiagen) at $-80^{\circ} \mathrm{C}$ until they were processed. Total RNA was isolated using the miRNeasy Mini Kit (Qiagen) and DNase digestion was performed as recommended. The cDNA was obtained by the GoScript ${ }^{\mathrm{TM}}$ Reverse Transcriptase Kit (Promega) according to the manufacturer's protocol.

For the RNA-sequencing, JKwt and JKCD69 cells were incubated for $4 \mathrm{~h}$ with $\mathrm{nLDL}$ moxLDL and hoxLDL as an exploratory study. RNA was quantified by spectrophotometry (ND-1000; NanoDrop Technologies) and RNA quality was determined by microcapillary electrophoresis on an Agilent 2001 Bioanalyzer (Agilent Technologies) with RNA 6000 Nanochips. The samples were sequenced by the Bioinformatics Unit and the Genomics Unit from the Centro Nacional de Investigaciones Cardiovasculares Carlos III (CNIC), Madrid, Spain. Fastq files were pre-processed by FastQC (Babraham Bioinformatics - FastQC A Quality Control tool for High Throughput, available online at: https://www.bioinformatics.babraham.ac.uk/projects/fastqc/), to assess reads-quality, and Cutadapt to trim sequencing reads [14]. Resulting reads were mapped against reference transcriptome GRCh38.91 and quantified using RSEM [15]. Expected expression counts calculated with RSEM were then processed with an analysis pipeline that used the Bioconductor package EdgeR for normalization (using TMM method) and expression ratio calculation, taking only into account those genes expressed with at least 1 count per million (CPM) in at least one sample [16]. We normalized the gene expression of every sample relative to its control for each cell line (LDL vs. untreated) and then we compared the changes detected with increasing LDL oxidation degrees in JKCD69 respect to JKwt. Because the lack of replicates, we performed two strategies. On the one hand, genes candidates were selected using a threshold of foldchange > 1.8 in JKCD69 cells treated with hoxLDL. Heatmap and clustering for those genes were accomplished using Galaxy web platform and the public server at usegalaxy.org. Original values were Log $(x+1)$-transformed, columns were clustered using Euclidean method and scaling the data by row. Principal Component Analysis (PCA) was performed using Minitab Statistical Software (Minitab, LLC, Pennsylvania, USA). On the other hand, the gene expression of selected genes was compared in JKCD69 incubated with moxLDL and hoxLDL to the control samples (JKwt samples and JKCD69 resting and $\mathrm{nLDL})$.

\section{Quantification of gene expression}

Total RNA from human tissues was isolated using TRIsure ${ }^{\mathrm{TM}}$ reagent (Bioline) and reverse transcribed into cDNA using the High Capacity cDNA Reverse Transcription Kit (Applied Biosystems). Gene expression for NR4A receptors in human samples and cell culture studies was evaluated by real-time PCR using the 
SensiFAST probe Hi-ROX mix (Bioline), the ABI PRISM 7900HT sequence detection system (Applied Biosystems) and specific Taqman probes (Applied Biosystems) for NR4A1, (Hs00172437_m1) and NR4A3 (Hs00175077_m1). Alternatively, mRNA levels were assessed with the GoTaq ${ }^{\circledR}$ qPCR Master Mix system (Promega) for SYBR Green real-time PCR analysis. The specific primers pairs (PD-1 forward CTC CAG GCA TGC AGA TCC, reverse GGC CTG TCT GGG GAG TCT A; CD69 forward CAA GTT CCT GTC CTG TGT GC, and reverse GAG AAT GTG TAT TGG CCT GGA; GAPDH forward AGC CAC ATC GCT CAG ACA C, reverse GCC CAA TAC GAC CAA ATC C) were designed using the Roche Life Science web (Penzberg, Germany) and synthesized by Metabion (Steinkirchen, Baviera, Germany). Detection of amplified products was performed with the CFX384 Touch $^{\text {TM }}$ Real-Time PCR detection system (Bio-Rad). Data were analysed with the 3.1 version of the CFX Manager software (Bio-Rad). The PCR protocol consisted of a first denaturation step of $10 \mathrm{~min}$ at $95^{\circ} \mathrm{C}$ followed by 40 cycles of $10 \mathrm{~s}$ at $95^{\circ} \mathrm{C}$ and at $60 \mathrm{~s}$ of annealing/extension step at $60^{\circ} \mathrm{C}$ and a $10 \mathrm{~s}$ at $95^{\circ} \mathrm{C}$ before the melting curve was achieved. The realtime qPCRs were performed in triplicate for all the targets. The relative mRNA levels were determined using the comparative threshold (CT) method after checking primers efficiency. Normalization was accomplished to $\beta$-actin (Hs99999903_m1; for human tissue samples) or GAPDH levels, which were found with no changes between the different conditions in the RNAseq. The relative mRNA levels were expressed as folds of change over untreated samples.

\section{Anti-CD69 antibodies assays}

Monoclonal antibody anti-CD69 employed was generated at the Hospital Universitario La Princesa (Madrid, Spain) as it has been previously described [17]. The JKwt and JKCD69 cells were cultured in

supplemented medium at $1 \cdot 10^{6} \mathrm{cell} / \mathrm{s} / \mathrm{ml}$ with the antibodies $(10 \mu \mathrm{g} / \mathrm{ml})$ and the crosslinker AffiniPure Fab Fragment Goat Anti-Mouse IgG, Fcy fragment specific ( $20 \mu \mathrm{g} / \mathrm{ml}$, Jackson ImmunoResearch) the time required. As isotype control, the mouse IgG2b kappa isotype control antibody $(10 \mu \mathrm{g} / \mathrm{ml}$, Thermo Fisher Scientific/Life) was engaged and crosslinker was also added to this condition.

\section{Analysis of protein levels by flow cytometry}

The protein levels were measured after different time points of incubation by flow cytometry in a FACS Canto cytometer and analyzed with FlowJo software (FlowJo, LLC). Cells were rinsed twice with PBS (1X) and resuspended with PBS and Ghost Dye Red 780 (1:1000 dilution, Tonbo Biosciences) for 30 min on ice. After that, cells were rinsed once with PBS- $0.2 \%$ Bovine Serum Albumin (BSA) (PanReac AppliChem) and resuspended in $50 \mu \mathrm{l}$ of this buffer with the PE anti-human CD279 (PD1) (EH12.2H7, 1:100 dilution, BioLegend) antibody for 30 min on ice. The analysis strategy was to compare the mean fluorescence intensity between treated and untreated live cells for oxLDL experiments. For anti-CD69 monoclonal antibody engagement experiments, samples were incubated with mouse serum (1:100 dilution, SigmaAldrich) for 15 min before adding the same volume with flow cytometry antibodies. Percentage of positive cells for PD-1 were represented at different times.

\section{NR4A3 interfering by siRNA and cyclosporine A assays}


Gene knockdown of NR4A3 was performed using ON-TARGETplus SMARTpool small interfering RNA (siRNA) and ON-TARGETplus Control Pool Non-targeting Pool as scramble (Horizon) by electroporation. Cells were washed once with Hanks' Buffered Saline Solution (HBSS, Lonza) and once with Opti-MEM reduced serum medium ( $G i b c o$ ) before electroporate. After $48 \mathrm{~h}$, specific knockdown was confirmed by RTqPCR of mRNA levels and experiments were performed. Cyclosporine A (CsA) $(5 \mu \mathrm{g} / \mathrm{ml}$, SML1018 from Sigma-Aldrich, Burlington, MA, United States), phorbol 12-myristate 13-acetate (PMA) (50 ng/ml, SigmaAldrich) and ionomycin (lo) $(1 \mu \mathrm{g} / \mathrm{ml}$, Sigma-Aldrich) were employed when indicated.

\section{Human artery sampling and preservation}

Abdominal aortic samples were collected from patients undergoing open repair surgery for abdominal aortic aneurysm at the Hospital de la Santa Creu i Sant Pau (Barcelona, Spain) and from multi-organ donors [18]. Written consent was obtained from all participating subjects. The study was approved by the local ethics committee and was conducted in accordance with the Declaration of Helsinki. Samples were split and processed for conventional histological staining/immunohistochemistry or frozen in liquid nitrogen and stored at $-80^{\circ} \mathrm{C}$ for RNA and protein extraction. The specimens for conventional staining/ immunohistochemistry were immersed in fixative solution (4\% paraformaldehyde/0.1 M phosphatebuffered saline, $\mathrm{pH}$ 7.4). After overnight treatment, they were sectioned into blocks and embedded in paraffin. Vessels were cut into $5-\mu \mathrm{m}$-thick sections that were mounted on coated glass microscope slides (FLEX IHC, Dako, Santa Clara, CA, USA) and stored at room temperature until tested. The presence of inflammation in the aortic samples from patients selected for this study was confirmed by hematoxylin and eosin staining. Healthy control aortas from multi-organ donors were macroscopically normal and devoid of inflammatory lesions as determined by hematoxylin and eosin staining.

\section{Western blot analysis}

Human specimen samples for western blotting were snap-frozen in liquid nitrogen and stored at $-80^{\circ} \mathrm{C}$. Human protein extracts were obtained using ice-cold lysis buffer as described [19]. Protein lysates were resolved using sodium dodecyl sulphate-polyacrilamide gel electrophoresis (SDS-PAGE) and transferred to polyvinylidene difluoride membranes (Immobilon, Merck-Millipore; Burlington MA, USA, IPVH00010). Blots were blocked with $5 \%$ non-fat dry milk in TBST buffer $(100 \mathrm{mM}$ sodium chloride, $10 \mathrm{mM}$ Tris-HCl pH $7.5,0.05 \%$ Tween-20) at room temperature for 1 hour. Membranes were then incubated overnight with mouse monoclonal antibodies against: PD-1 (ab52587, Abcam, Cambridge, UK), CD69 (sc-373799, Santa Cruz Biotechnology, Inc., Dallas, TX, USA) or NOR-1 (H00008013-M06, Abnova, Taipei, Taiwan).

Appropriate horseradish peroxidase-conjugated secondary antibodies (Dako) and the Luminata ${ }^{\mathrm{TM}}$ Western HRP Substrate (Immobilon, Merck-Millipore) were used to detect bound antibodies. The size of detected proteins was estimated using protein molecular-mass standards (Hyperpage Prestained Protein Marker; Bioline, Paris, France). B-actin (A5441, Sigma-Aldrich) was used to verify equal loading of protein on each lane.

\section{Immunohistochemical analysis}


Tissue sections ( $5 \mu \mathrm{m}$-thick) were de-paraffinised in xylene, rehydrated in graded ethanol solutions and subjected to heat-induced antigen retrieval either in $10 \mathrm{mM}$ citrate buffer at pH 6 (for CD69 and NOR-1 detection) or in Tris-EDTA buffer pH 9.0 (for PD1 detection). Then, slides were treated with $3 \%$ hydrogen peroxide in methanol for $30 \mathrm{~min}$ to block endogenous peroxidase activity. Subsequently, slides were incubated with $10 \%$ normal serum and endogenous avidin and biotin blocked using a commercial kit (Vector Laboratories, Burlingame, CA, USA). Then samples were incubated overnight at $4^{\circ} \mathrm{C}$ with the following primary antibodies against: PD-1 (ab237728, Abcam) CD69 (sc-373799, Santa Cruz Biotechnology, Inc.) or NOR-1 (H00008013-M06, Abnova). Samples were washed and then incubated with the appropriate biotinylated secondary antibodies for $1 \mathrm{~h}$ (Vector Laboratories, Burlingame, CA, USA). After washing three times in PBS, the avidin-biotin peroxidase complex (ABC, Vector Laboratories) was added for $30 \mathrm{~min}$. Color was developed by incubation with 3,3'-diaminobenzidine (DAB) and then sections were counterstained with haematoxylin, dehydrated, cleared and mounted. Samples in which the primary antibody was omitted were used as negative controls.

\section{Statistical Analyses}

Data were analyzed with GraphPad Prism 7.04 (GraphPad Software, San Diego, CA, USA). Significance differences were determined by Two-way ANOVA when both cell lines were used with different treatments and One-way ANOVA to compare more than two means with one cell line. Tukey or Bonferroni post hoc tests were used to perform multiple comparisons as indicated. To compare two means in interfering experiments, unpaired $t$ test and paired $t$ test were used when appropriate. Differences from human samples experiments were analysed with Mann-Whitney test and Pearson Product Moment Correlation was applied. Differences were considered significant at $P<0.05$.

\section{Results}

\section{OxLDL-CD69 binding induces a differential transcriptional response in human T lymphocytes}

To identify genes differentially expressed in response to the binding of oxLDL to CD69, JKCD69 and JKwt cells were incubated in the presence or absence of $n L D L$, and copper-oxidized LDL at two different degrees of oxidation, moxLDL and hoxLDL. To focus in those genes modified by hoxLDL in JKCD69 T cells, we used a cut-off of fold change $>1.8$ and we identified 577 upregulated and 238 downregulated genes in this condition. Principal Component Analysis of these genes in all of the samples were represented (Fig. 1A). Statistical analysis showed clear differences in gene expression profile depending on the degree of LDL oxidation and the presence or absence of CD69 (Fig. 1A). Native LDL-treated cells exhibited similar expression profiles to those of untreated cells (Fig. 1A). The differences displayed in PCA analysis are reflected on the heat map clustering (Fig. 1B). JKCD69 cells incubated with hoxLDL displayed deeper differences in gene expression compared both with moxLDL and in JKwt (Fig. 1A, B). Differences elicited by lipoproteins based on their oxidation degree are in line with previous studies[2022]. Interestingly, we identified PD-1 as one of the genes with higher levels of induction in JKCD69 vs. 
JKwt in response to oxLDL (Table 1; Supplementary Data 1). As an internal control, we identified increased expression of NR4A receptors, especially NR4A3, in JKCD69 treated with hoxLDL compared to JKwt treated with hoxLDL or JKCD69 cells treated or not with nLDL (Table 1).

Table 1

$\begin{aligned} & \text { Potential genes of interest differentially } \\
& \text { expressed in JKCD } 69\end{aligned}$
vs. JKwt in
\begin{tabular}{|ll|}
\hline response to the CD69-oxLDL binding. \\
\hline Official Gene Symbol & Fold Change \\
\hline PDCD-1 & 4.91 \\
\hline ENTPD1 & 3.33 \\
\hline KCNMB1 & 3.09 \\
\hline ENPP1 & 2.64 \\
\hline NR4A3 & 2.41 \\
\hline TLR6 & 1.93 \\
\hline NR4A1 & 1.82 \\
\hline PDGFC & 0.65 \\
\hline TNFRSF4 & 0.64 \\
\hline RETN & 0.63 \\
\hline IL26 & 0.51 \\
\hline CCR8 & 0.35 \\
\hline
\end{tabular}

\begin{tabular}{|lll|}
\hline \multicolumn{2}{|l}{ Table 2. Clinical features of patients and controls } \\
\hline Clinical parameters & Controls $(n=11)$ & Patients $(n=49)$ \\
\hline Age (years \pm SEM) & $61 \pm 5.4$ & $71.3 \pm 0.66$ \\
\hline Males (\%) & 91 & 100 \\
\hline Smoking (\%)* & 55 & 81.6 \\
\hline Hypertension (\%) & 64 & 67.3 \\
\hline Diabetes (\%) & 36 & 10.2 \\
\hline Hyperlipidemia (\%) & 27 & 57.1 \\
\hline Ischemic cardiomyopathy (\%) & 0 & 18.4 \\
\hline * Current and ex-smokers; SEM, standard error of the mean. \\
\hline
\end{tabular}




\section{OxLDL-CD69 binding increases PD-1 expression}

To confirm that oxLDL binding to CD69 upregulates PD-1 in T cells, the expression of PD-1 was assessed by real time-PCR (RT-PCR) in JKCD69 and JKwt cells treated with hoxLDL. PD-1 mRNA levels were significantly increased in JKCD 69 after $4 \mathrm{~h}$ of incubation with oxLDL compared with JKwt cells, while nLDL did not induce PD-1 expression in either cell line (Fig. 1C). Flow cytometry analysis showed that oxLDL increased PD-1 surface expression in JKCD69 compared to JKwt at $48 \mathrm{~h}$, while no significant changes were elicited by nLDL (Fig. 1D, E).

To evaluate the specificity of CD69, we assessed whether engagement of CD69 with specific antibodies triggers a similar response than oxLDL. JKwt and JKCD69 cells were cultured in the presence or absence of a CD69 agonistic antibody for $4 \mathrm{~h}$ and mRNA levels were analysed by RT-PCR. In JKCD69 cells, the antibody significantly increased PD-1 mRNA levels at $4 \mathrm{~h}$ (Fig. 2A). It also increased the amount of PD-1 detected on the cell membrane, with a peak expression at $48 \mathrm{~h}$ (Fig. 2B), similar to the induction effect observed with oxLDL. The agonistic antibody also induced expression of NR4A1 and specially NR4A3 (Fig. 2C, D). No significant effects on gene expression were observed in T cells devoid of CD69 (JKwt).

\section{PD-1 induction through CD69 engagement is regulated by NFAT}

CD69 crosslinking triggers a mobilization of $\mathrm{Ca}^{2+}$ extracellular influx as well as the activation of NFAT proteins [23-25]. Moreover, NFATc1 is involved in the transcriptional regulation of PD-1 [26]. Thus, we probed whether NFAT activation was responsible for the induction of PD-1 through CD69 binding. Treatment with CsA, which impairs the dephosphorylation of NFAT by calcineurin and its recruitment to the nucleus, prevented the induction of PD-1 and the NR4A3 mRNA expression triggered by CD69 activation or the combination of PMA and ionomycin (Fig. 3A, B) [27]. However, CsA did not affect NR4A1 mRNA expression induced by CD69 (Fig. 3C). In order to determine the contribution of NR4A3 to the regulation of PD-1 expression, we inhibited NR4A3 expression using a specific siRNA (Fig. 3D). Interestingly, silencing NR4A3 slightly upregulated PD-1 expression upon induction with both anti-CD69 and PMA/lo stimulation in JKCD69 cells (Fig. 3E).

\section{PD-1 and CD69 are highly expressed in inflamed human arteries}

To assess whether CD69 and PD-1 upregulation is associated to chronic vascular inflammatory disease, CD69, PD-1 and NR4A3 mRNA expression was analysed by RT-PCR in inflamed abdominal aortic samples from aneurysm patients undergoing open repair surgery $(n=49)$ and healthy abdominal aorta from multiorgan donors $(n=11)$. The clinical and demographic data of the patients and donors are collected in Table 2. CD69 and PD-1 were highly and differentially expressed in inflamed aortas and their mRNA levels showed a strong positive correlation $(r=0.655 p<0.0001)$ (Fig. 4A). In addition, CD69 and PD-1 proteins 
levels were also increased in diseased aortas, as determined by Western blotting (Fig. 4B). NR4A3 expression (mRNA and protein) was also upregulated in inflamed aortas, as expected (Fig. 4B, C). Furthermore, immunohistochemical analysis of consecutive aortic sections revealed high CD69 and PD1 immunostaining in areas enriched in inflammatory cells (Fig. 4D, left and middle panels), and a similar pattern was observed for NR4A3 (Fig. 4D, right panels).

\section{Discussion}

In this work, we identify a novel TCR-independent induction mechanism of PD-1 through the engagement of CD69 by oxLDL. RNA-Seq analysis of JKwt and JKCD69 cultured with LDL oxidized to a different degree revealed a CD69-dependent and LDL oxidation-dependent response. Cells left untreated or treated with native LDL displayed similar expression profiles, while oxLDL produced differences in gene expression that are more pronounced in JKCD69. These results underscore the specificity of CD69 for oxLDL and identified specific responses triggered by CD69-oxLDL binding. Interestingly, PD-1 was found to be one of the most overrepresented mRNA in JKCD69 cells treated with oxLDL. As expected, oxLDL markedly elevated the expression of NR4A3 and also NR4A1 [8]. In vitro assays confirmed the mRNA and protein induction of PD-1 in JKCD69 in presence of highly oxLDL. The specificity of the signal and the dependence of NR4A and PD-1 induction through CD69 in T cells was confirmed using an agonist antiCD69 monoclonal antibody.

PD-1 expression is transiently induced by activating stimuli such as PMA and ionomycin, concanavalin A, anti-CD3/CD28 antibodies or by antigen-TCR engagement and cytokine receptor engagement [28, 29]. Extracellular influx of $\mathrm{Ca}^{2+}$ induces the expression of NFAT regulated genes through calcineurin activation, including PD-1. [26]. Our data highlight the role of NFAT as a transcriptional regulator involved in the expression of PD-1 and NR4A3 induced by CD69. However, the expression of NR4A1 was not affected following NFAT inactivation. These results are in accordance with previous studies that evaluated the sensitivity of the NR4A subfamily of nuclear receptors to NFAT pathway inhibitors in mice [30]. However, our data also revealed a slightly increased expression of PD-1 in NR4A3-silenced cells treated with anti-CD69 or with PMA/lo stimulation. Accordingly, recent studies have confirmed a relationship between the expression of NR4A receptors and PD-1 in T cells [31, 32]. Hence, the three NR4A proteins regulate the accessibility of an enhancer located at $\sim 23 \mathrm{~kb} 5^{\prime}$ of the $P d-1$ transcription start site (TSS) in a number of murine models for exhausted CD8 + T cells [32]. The upregulation of hoxLDLinduced NR4A3 might be functioning as a negative feedback loop to counter-regulate the expression of PD-1 induced by CD69.

The PD-1/PD-L1 pathway contribution in cardiovascular diseases has been thoroughly studied. $P d-1$ and Ldlr double knockout mice developed larger atherosclerotic lesions with higher CD $4+$ and CD $8+T$ cells and macrophages cell numbers [29]. PD-1 blockade increased atherosclerotic lesion inflammation in hypercholesterolemic $\mathrm{Ldll}^{-/-}$mice suggesting that PD-1 acts as negative regulator of inflammation in atherosclerosis [29]. Accordingly, cardiovascular complications from immune checkpoint inhibitors therapies as PD-1 and PD-L1 inhibitors are an emerging concern that merits further investigation [33]. Our 
analysis from inflamed abdominal aortic samples revealed a strong correlation between PD-1 and CD69 mRNA expression. Moreover, more than half of the patients analyzed had hyperlipidemia.

Immunohistochemical analyses revealed strong expression of PD-1, CD69 and NR4A3 in areas enriched in inflammatory cells, in which the regulation of PD-1 through CD69 and NR4A3 might contribute to this chronic vascular inflammatory disease.

Our study identifies a new function of CD69 by promoting PD-1 expression in T lymphocytes after the engagement with oxLDL that might be responsible for the exacerbated activation state found in absence of CD69 in the atherosclerosis model. The discovery of this regulation underscores the relevant role of these molecules in inflammatory cardiovascular diseases and provides new knowledge for developing therapeutic strategies.

\section{Declarations}

\section{Conflict of interest}

The authors have no conflict of interest to declare.

\section{Sources of funding}

This work was supported by grant S2017/BMD-3671-INFLAMUNE-CM from the Comunidad de Madrid, a grant from the Ramón Areces Foundation "Ciencias de la Vida y la Salud", from "La Caixa" Banking Foundation (HR17-00016) to FS-M; grant from the Spanish Ministerio de Ciencia e Innovación (PDI-2020120412RB-I00 to FS-M); grants (RTI2018-094727-B-100) and the Agència de Gestiód'AjutsUniversitarisi de Recerca (AGAUR) (2017-SGR-00333) to JM-G; and a grant from the Instituto de Salud Carlos III (PI18/0919) to CR. M. Jiménez-Fernández is supported by a FPI-Severo Ochoa-CNIC; C. Ballester-Servera is supported by a FPU fellowship (Ministerio de Universidades).

\section{Data availability}

The data underlying this article are available in the article and in its online Supplementary material.

\section{References}

1. González-Amaro R, Cortés JR, Sánchez-Madrid F, Martín P (2013) Is CD69 an effective brake to control inflammatory diseases? Trends Mol Med 19:625-632. https://doi.org/10.1016/j.molmed.2013.07.006

2. Radulovic K, Manta C, Rossini V, Holzmann K, Kestler HA, Wegenka UM, Nakayama T, Niess JH (2012) CD69 Regulates Type I IFN-Induced Tolerogenic Signals to Mucosal CD4 T Cells That Attenuate Their Colitogenic Potential. J Immunol 188:2001-2013 . https://doi.org/10.4049/jimmunol.1100765 
3. Sancho D, Gómez M, Viedma F, Esplugues E, Gordón-Alonso M, Angeles García-López M, de la Fuente H, Martínez-A C, Lauzurica P, Sánchez-Madrid F (2003) CD69 downregulates autoimmune reactivity through active transforming growth factor- $\beta$ production in collagen-induced arthritis. J Clin Invest 112:872-882 . https://doi.org/10.1172/JCl200319112

4. Cortés JR, Sánchez-Díaz R, Bovolenta ER, Barreiro O, Lasarte S, Matesanz-Marín A, Toribio ML, Sánchez-Madrid F, Martín P (2014) Maintenance of immune tolerance by Foxp3+ regulatory T cells requires CD69 expression. J Autoimmun 55:51-62 . https://doi.org/10.1016/j.jaut.2014.05.007

5. Radstake TRDJ, van Bon L, Broen J, Wenink M, Santegoets K, Deng Y, Hussaini A, Simms R, Cruikshank WW, Lafyatis R (2009) Increased Frequency and Compromised Function of T Regulatory Cells in Systemic Sclerosis (SSc) Is Related to a Diminished CD69 and TGF $\beta$ Expression. PLoS One 4:e5981 . https://doi.org/10.1371/journal.pone.0005981

6. Yu L, Yang F, Zhang F, Guo D, Li L, Wang X, Liang T, Wang J, Cai Z, Jin H (2018) CD69 enhances immunosuppressive function of regulatory T-cells and attenuates colitis by prompting IL-10 production. Cell Death Dis 9: . https://doi.org/10.1038/s41419-018-0927-9

7. Sánchez-Díaz R, Blanco-Dominguez R, Lasarte S, Tsilingiri K, Martín-Gayo E, Linillos-Pradillo B, de la Fuente H, Sánchez-Madrid F, Nakagawa R, Toribio ML, Martín P (2017) Thymus-Derived Regulatory T Cell Development Is Regulated by C-Type Lectin-Mediated BIC/MicroRNA 155 Expression. Mol Cell Biol 37:1-18 . https://doi.org/10.1128/mcb.00341-16

8. Tsilingiri K, De La Fuente H, Relaño M, Sánchez-Díaz R, Rodríguez C, Crespo J, Sánchez-Cabo F, Dopazo A, Alonso-Lebrero JL, Vara A, Vázquez J, Casasnovas JM, Alfonso F, Ibáñez B, Fuster V, Martínez-González J, Martín P, Sánchez-Madrid F (2019) Oxidized Low-Density Lipoprotein Receptor in Lymphocytes Prevents Atherosclerosis and Predicts Subclinical Disease. Circulation 139:243-255 . https://doi.org/10.1161/CIRCULATIONAHA.118.034326

9. Wherry EJ (2011) T cell exhaustion. Nat Immunol 12:492-499 . https://doi.org/10.1038/ni.2035

10. Martín P, Blanco-Domínguez R, Sánchez-Díaz R (2021) Novel human immunomodulatory T cell receptors and their double-edged potential in autoimmunity, cardiovascular disease and cancer. Cell Mol Immunol 18:919-935 . https://doi.org/10.1038/s41423-020-00586-4

11. Qin W, Hu L, Zhang X, Jiang S, Li J, Zhang Z, Wang X (2019) The Diverse Function of PD-1/PD-L Pathway Beyond Cancer. Front Immunol 10: . https://doi.org/10.3389/fimmu.2019.02298

12. Sharpe AH, Wherry EJ, Ahmed R, Freeman GJ (2007) The function of programmed cell death 1 and its ligands in regulating autoimmunity and infection. Nat Immunol 8:239-245. https://doi.org/10.1038/ni1443

13. Calvayrac 0 , Rodríguez-Calvo R, Alonso J, Orbe J, Martín-Ventura JL, Guadall A, Gentile M, JuanBabot O, Egido J, Beloqui O, Paramo JA, Rodríguez C, Martínez-González J (2011) CCL20 Is Increased in Hypercholesterolemic Subjects and Is Upregulated By LDL in Vascular Smooth Muscle Cells. Arterioscler Thromb Vasc Biol 31:2733-2741 . https://doi.org/10.1161/ATVBAHA.111.235721

14. Martin M (2011) Cutadapt removes adapter sequences from high-throughput sequencing reads. EMBnet.journal 17:10-12 . https://doi.org/10.14806/EJ.17.1.200 
15. Li B, Dewey CN (2011) RSEM: Accurate transcript quantification from RNA-Seq data with or without a reference genome. BMC Bioinformatics 12:1-16 . https://doi.org/10.1186/1471-2105-12323/TABLES/6

16. Robinson MD, McCarthy DJ, Smyth GK (2010) edgeR: a Bioconductor package for differential expression analysis of digital gene expression data. Bioinformatics 26:139-140 . https://doi.org/10.1093/BIOINFORMATICS/BTP616

17. Cebrián M, Yagüe E, Rincón M, López-botet M, De Landázuri MO, Sánchez-madrid F (1988) Triggering of $t$ cell proliferation through aim, an activation inducer molecule expressed on activated human lymphocytes. J Exp Med 168:1621-1637 . https://doi.org/10.1084/jem.168.5.1621

18. Cañes L, Alonso J, Ballester-Servera C, Varona S, Escudero JR, Andrés V, Rodríguez C, MartínezGonzález J (2021) Targeting Tyrosine Hydroxylase for Abdominal Aortic Aneurysm: Impact on Inflammation, Oxidative Stress, and Vascular Remodeling. Hypertension 78:681-692 . https://doi.org/10.1161/HYPERTENSIONAHA.121.17517

19. Clemente C, Rius C, Alonso-Herranz L, Martín-Alonso M, Pollán Á, Camafeita E, Martínez F, Mota RA, Núñez V, Rodríguez C, Seiki M, Martínez-González J, Andrés V, Ricote M, Arroyo AG (2018) MT4-MMP deficiency increases patrolling monocyte recruitment to early lesions and accelerates atherosclerosis. Nat Commun 9: . https://doi.org/10.1038/s41467-018-03351-4

20. Damián-Zamacona $S$, Toledo-lbelles $P$, Ibarra-Abundis $M$, Uribe-Figueroa $L$, Hernández-Lemus $E$, Macedo-Alcibia KP, Delgado-Coello B, Mas-Oliva J, Reyes-Grajeda JP (2016) Early transcriptomic response to Idl and oxldl in human vascular smooth muscle cells. PLoS One 11: . https://doi.org/10.1371/journal.pone.0163924

21. Lara-Guzmán OJ, Gil-Izquierdo Á, Medina S, Osorio E, Álvarez-Quintero R, Zuluaga N, Oger C, Galano J-M, Durand T, Muñoz-Durango K (2018) Oxidized LDL triggers changes in oxidative stress and inflammatory biomarkers in human macrophages. Redox Biol 15:1-11. https://doi.org/10.1016/j.redox.2017.11.017

22. Hermansson A, Ketelhuth DFJ, Strodthoff D, Wurm M, Hansson EM, Nicoletti A, Paulsson-Berne G, Hansson GK (2010) Inhibition of T cell response to native low-density lipoprotein reduces atherosclerosis. J Exp Med 207:1081-1093 . https://doi.org/10.1084/jem.20092243

23. Bikah G, Pogue-Caley RR, McHeyzer-Williams LJ, McHeyzer-Williams MG (2000) Regulating T helper cell immunity through antigen responsiveness and calcium entry. Nat Immunol 1:402-412 . https://doi.org/10.1038/80841

24. D'Ambrosio D, Trotta R, Vacca A, Frati L, Santoni A, Gulino A, Testi R (1993) Transcriptional regulation of interleukin-2 gene expression by CD69-generated signals. Eur J Immunol 23:2993-2997 . https://doi.org/10.1002/eji.1830231140

25. Rao A, Luo C, Hogan PG (1997) Transcription factors of the NFAT family: Regulation and function. Annu Rev Immunol 15:707-747 . https://doi.org/10.1146/annurev.immunol.15.1.707

26. Oestreich KJ, Yoon H, Ahmed R, Boss JM (2009) NFATc1 Regulates Programmed Death-1 Expression Upon T Cell Activation 1. 181:4832-4839 
27. Fruman DA, Klee CB, Bierer BE, Burakoff SJ (1992) Calcineurin phosphatase activity in $T$ lymphocytes is inhibited by FK 506 and cyclosporin A. Proc Natl Acad Sci 89:3686-3690 . https://doi.org/10.1073/pnas.89.9.3686

28. Gianchecchi E, Fierabracci A (2018) Inhibitory receptors and pathways of lymphocytes: The role of PD-1 in Treg development and their involvement in autoimmunity onset and cancer progression. Front Immunol 9:1-12 . https://doi.org/10.3389/fimmu.2018.02374

29. Bu DX, Tarrio M, Maganto-Garcia E, Stavrakis G, Tajima G, Lederer J, Jarolim P, Freeman GJ, Sharpe AH, Lichtman AH (2011) Impairment of the programmed cell death-1 pathway increases atherosclerotic lesion development and inflammation. Arterioscler Thromb Vasc Biol 31:1100-1107 . https://doi.org/10.1161/ATVBAHA.111.224709

30. Jennings E, Elliot TAE, Thawait N, Kanabar S, Yam-Puc JC, Ono M, Toellner K-M, Wraith DC, Anderson G, Bending D (2020) Nr4a1 and Nr4a3 Reporter Mice Are Differentially Sensitive to T Cell Receptor Signal Strength and Duration. Cell Rep 33:108328 . https://doi.org/10.1016/j.celrep.2020.108328

31. Liu X, Wang Y, Lu H, Li J, Yan X, Xiao M, Hao J, Alekseev A, Khong H, Chen T, Huang R, Wu J, Zhao Q, Wu Q, Xu S, Wang X, Jin W, Yu S, Wang Y, Wei L, Wang A, Zhong B, Ni L, Liu X, Nurieva R, Ye L, Tian Q, Bian X-W, Dong C (2019) Genome-wide analysis identifies NR4A1 as a key mediator of T cell dysfunction. Nature 567:525-529 . https://doi.org/10.1038/s41586-019-0979-8

32. Chen J, López-Moyado IF, Seo H, Lio C-WJ, Hempleman LJ, Sekiya T, Yoshimura A, Scott-Browne JP, Rao A (2019) NR4A transcription factors limit CAR T cell function in solid tumours. Nature 567:530534 . https://doi.org/10.1038/s41586-019-0985-x

33. Hu JR, Florido R, Lipson EJ, Naidoo J, Ardehali R, Tocchetti CG, Lyon AR, Padera RF, Johnson DB, Moslehi J (2019) Cardiovascular toxicities associated with immune checkpoint inhibitors. Cardiovasc Res 115:854-868 . https://doi.org/10.1093/cvr/cvz026

\section{Figures}

\section{Figure 1}

OxLDL-CD69 binding induces a differential transcriptional response increasing the PD-1 expression. A) Principal Component Analysis (PCA) performed using the up- and down-regulated genes from the RNASeq data of each incubation condition. The proportion of variability explained by each Principal Component (PC1 and PC2) are included in the axis. Blue samples correspond to JKwt and red samples to JKCD69. (nLDL: native LDL; moxLDL: moderately oxidized LDL; hoxLDL. highly oxidized LDL).B) The oxidation degree of oxLDL inducesa differential transcriptomic response. Heatmap based on the foldchange of 577 upregulated and 242 downregulated genes in JKCD69 with the higher level of oxLDL. Data are shown as $\operatorname{Ln}(\mathrm{x}+1)$ and are clustered using correlation distance and average linkage. Up- and downregulated genes are showninred and blue respectively. C) Relative expression of PD-1 mRNA in JKCD69 
and JKwt treated with hoxLDL. Data are mean $\pm \operatorname{SEM}(\mathrm{n}=3)$ and were analysed with two-way ANOVA (Tukey post hoc test). * indicates significant differences $(P<0.05)$ with the treatment for each cell line (native vs. oxLDL), \# JKCD69 vs. JKwt in the same condition, o significant differences respect the previous time ( $45^{\prime} v s .4 \mathrm{~h}, 4 \mathrm{~h} v s .8 \mathrm{~h}$ ). D) Mean fluorescence intensity of PD-1 in both cell lines at different time points. Data are mean \pm SEM $(n=3)$ and were analysed with Two-way ANOVA (Bonferroni post hoc test). * indicates significant differences $(P<0.05)$ in the treatment for each cell line (native vs oxLDL), \# JKCD69 vs. JKwt in the same condition, o significant differences respect the time. E) Histograms of a representative experiment of the induction of PD-1 in JKCD69 and JKwt after $48 \mathrm{~h}$ incubated with LDLs.

\section{Figure 2}

CD69 engagement induces the PD-1 mRNA and protein expression. A) Relative expression of PD-1 mRNA induced by anti-CD69 TP1/55 antibody in JKCD69 after 4h of stimulation. JKwt cells response was assessed as a control. An isotype control antibody was also used. Data are mean $\pm S E M(n=3)$ and ** $P<0.01$ differences were determined with Two-way ANOVA(Tukey post hoc test). B) Mean fluorescence intensity of PD-1 in both cell lines at different time points after engagement of the CD69 agonistic antibody TP1/55. Data are mean \pm SEM $(n=3)$ and differences were analysed with Two-way ANOVA (Tukey post hoc test). * indicates significant differences $(P<0.05)$ with the treatment for each cell line (antibodyvs. isotype control), \# JKCD69 vs. JKwt in the same condition, o significant differences respect the previous time ( $24 \mathrm{~h} v s .48 \mathrm{~h}, 48 \mathrm{~h}$ vs. $72 \mathrm{~h}$ ).C)Relative expression of NR4A1 mRNA induced by antiCD69 TP1/55 antibody in JKCD69 after 4 hour. Data are mean \pm SEM $(n=3)$ and differences were analysed with Two-way ANOVA (Bonferroni post hoc test). ${ }^{*} P<0.01$. $* \star * ~ P<0.001$.D)Relative expression of NR4A3 mRNA induced in JKCD69 after 4 hour of incubation with anti-CD69 antibody. Data are mean \pm SEM $(n=3)$ and differences were analysed with Two-way ANOVA (Bonferroni post hoc test). ** $P<0.01$. *** $P<0.001$.

\section{Figure 3}

NFAT regulates PD-1 expression induced by CD69 engagement in T cells. A)Cyclosporine A reduces the expression of PD-1+ in T cells. JKCD69 cells were incubated with crosslinked anti-CD69 with or without cyclosporine A (CSA), or phorbol 12-myristate 13-acetate and ionomycin (PMA/lo) stimulated with or without CsA for $48 \mathrm{~h}$. Data are mean \pm SEM $(n=3)$ and differences were determined by unpaired $t$ test. * $P<0.05$. B) Cyclosporine A inhibits CD69-mediated NR4A3 induction. Relative expression of NR4A3 in JKCD69 incubated with anti-CD69 monoclonal antibody, with or without CsA and with CsA in resting cells for $4 \mathrm{~h}$. Data are mean $\pm \operatorname{SEM}(\mathrm{n}=3)$ and differences were analysed with One-way ANOVA (Tukey post hoc test). ${ }^{*}<0.05$, $\left.* * P<0.01 . C\right)$ Induction of NR4A1 is independent of NFAT blockade. Relative expression of NR4A1 in JKCD69 with anti-CD69 antibody, with or without CsA and with CsA in resting cells incubated for 4 h. Data are mean \pm SEM $(n=3)$ and were analysed with One-way ANOVA (Tukey post hoc test). * 
$P<0.05$, ** $P<0.01 . D)$ Relative expression levels of NR4A3 mRNA after siRNA knockdown in resting and anti-CD69 stimulation conditions. Data showed are mean \pm SEM $(n=3)$ and differences were determined by unpaired $t$ test. * $P<0.05$.E)siRNAinterfering of NR4A3 expression enhances PD-1+ cell population. JKCD 69 were stimulated with antiCD 69 or PMA/lo for $48 \mathrm{~h}$. Data are mean \pm SEM $(n=3)$ and differences were determined by paired $t$ test. * $P<0.05$.

\section{Figure 4}

PD-1 and CD69 are highly expressed in inflamed human arteries. A) PD-1 and CD69 mRNA levels were measured in inflamed abdominal aortic samples (IAA) from patients undergoing open repair surgery for abdominal aortic aneurysm $(n=49)$ and healthy abdominal aortic samples (HAA) from donors $(n=11)$. Data are expressed as mean $\pm S E M * P<0.05$ (Mann-Whitney test).(right panel) Statistically significant positive correlation between CD69 mRNA levels and those corresponding to PD-1 in inflamed aortic samples from patients. The Pearson Product Moment Correlation was applied. B) CD69, PD-1 and NR4A3 protein levels were evaluated by western blot in aortic lysates from IAA and HAA samples. Representative immunoblots are shown. C) NR4A3 mRNA levels assessed in the samples described in A). Data are expressed as mean \pm SEM. ${ }^{*} P<0.05$ (Mann-Whitney test). D) Immunohistochemicalanalysis of CD69, PD1 and NR4A3 in haematoxylin counterstained sections from IAA and HAA samples. The indicated areas are shown at high magnification (middle panels). Bar: $100 \mu \mathrm{m}$ (upper and lower panels) and $50 \mu \mathrm{m}$ (middle panels). Negative controls in which the primary antibody was omitted are shown on the right.

\section{Supplementary Files}

This is a list of supplementary files associated with this preprint. Click to download.

- RNAseqsupplementarydata.xIsx 